\title{
Customer Responses to Service Failure in Direct and Indirect Harm Context: An Abstract
}

\author{
Hyunju Shin and Riza Casidy
}

\begin{abstract}
While extant research has examined customer evaluations of service recovery aimed at other customers, little is known about whether customers react differently to the same recovery depending on whether they are victims or observers of a service failure. This paper aims to compare the influence of service recovery on customer responses to service failure directed at themselves vs. other customers. This study used a $2 \times 3$ between-subject quasi-experimental design using written scenarios and surveys to test the research hypotheses in a professional services context. The analysis reveals that the effect of service recovery is weaker on customer forgiveness among victims than observers. In addition, when compensation is offered, victims show higher levels of distributive justice but lower levels of interactional justice than mere observers. This research sheds light on findings in the service recovery literature by outlining the differential reactions customers demonstrate at the experience of service failure directed at themselves vs. others. This study provides insights into how practitioners might attenuate the negative effect of service failure for those who are either directly or indirectly affected by failed service encounters.
\end{abstract}

\author{
H. Shin $(\bowtie)$ \\ Georgia Southern University, Statesboro, GA, USA \\ e-mail: hshin@georgiasouthern.edu \\ R. Casidy \\ Deakin University, Burwood, VIC, Australia \\ e-mail: riza.casidy@deakin.edu.au
}

